\title{
Polymer-ligated Uniform Lead Chalcogenide Nanoparticles with Tunable Size and Robust Stability Enabled by Judiciously- Designed Surface Chemistry
}

Shuang Liang ${ }^{1,2}$, Mingyue Zhang ${ }^{1}$, Yanjie He ${ }^{1}$, Zhitao Kang, ${ }^{1,3}$ Mengkun Tian, ${ }^{4}$ Meng Zhang, ${ }^{1}$

Han Miao, ${ }^{1}$ and Zhiqun $\operatorname{Lin}^{1 *}$

1. School of Materials Science and Engineering, Georgia Institute of Technology, Atlanta, GA 30332, USA.

2. School of Chemical and Biomolecular Engineering, Georgia Institute of Technology, Atlanta, GA 30332, USA.

3. Georgia Tech Research Institute, Georgia Institute of Technology, Atlanta, GA 30332, USA.

4. The Institute for Electronics and Nanotechnology, Georgia Institute of Technology, Atlanta, GA 30332, USA.

Corresponding Author: zhiqun.lin@mse.gatech.edu 
Tables, Figures and Figure captions

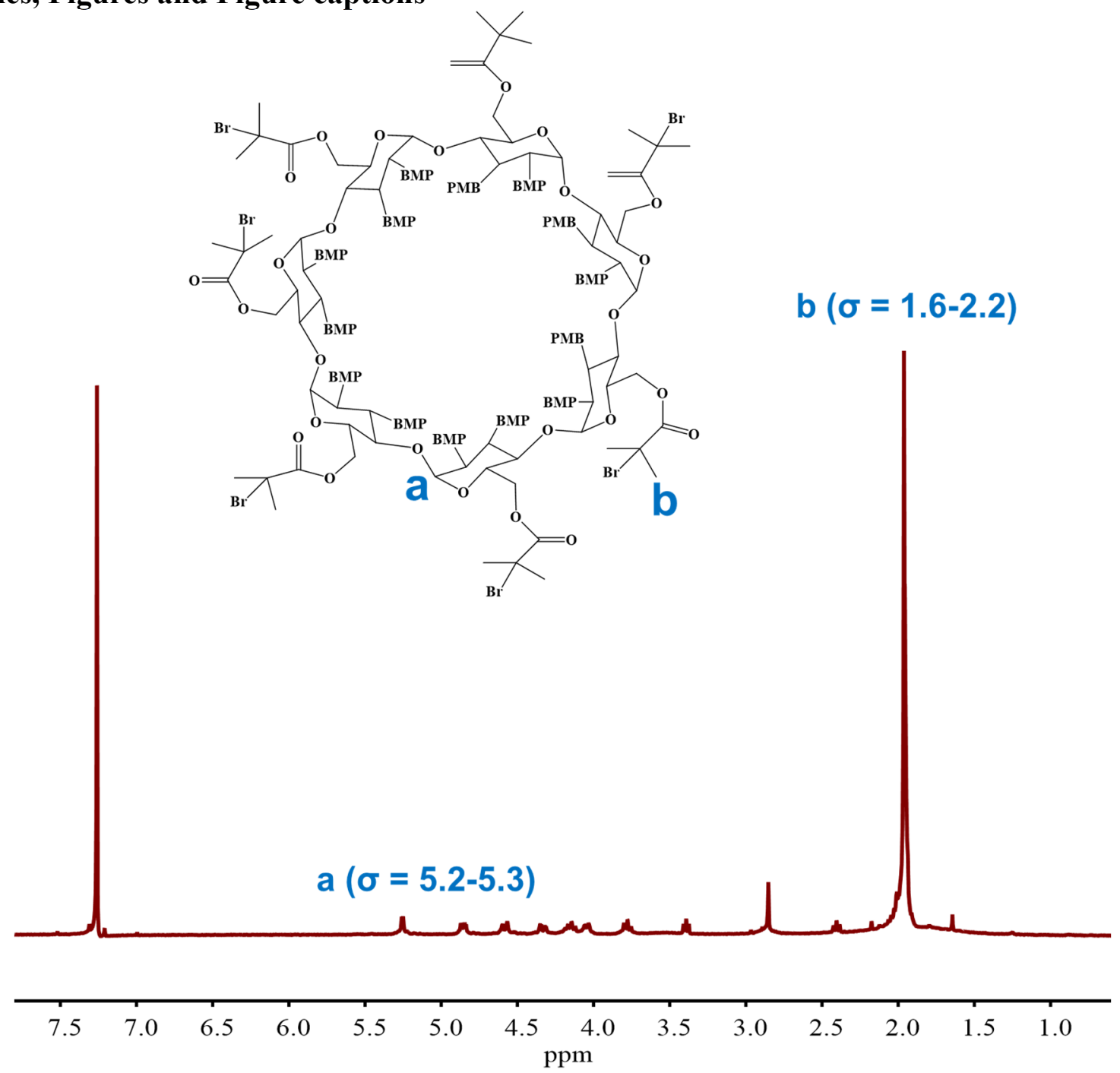

Figure S1. ${ }^{1} \mathrm{H}$ NMR spectrum of heptakis[2,3,6-tri-O-(2-bromo-2-methylpropionyl]- $\beta$ cyclodextrin macroinitiator (denoted $\mathrm{Br}-\beta-\mathrm{CD}$ ) with $\mathrm{CDCl}_{3}$ as solvent. BMP: 2-bromo-2methylpropionate. 


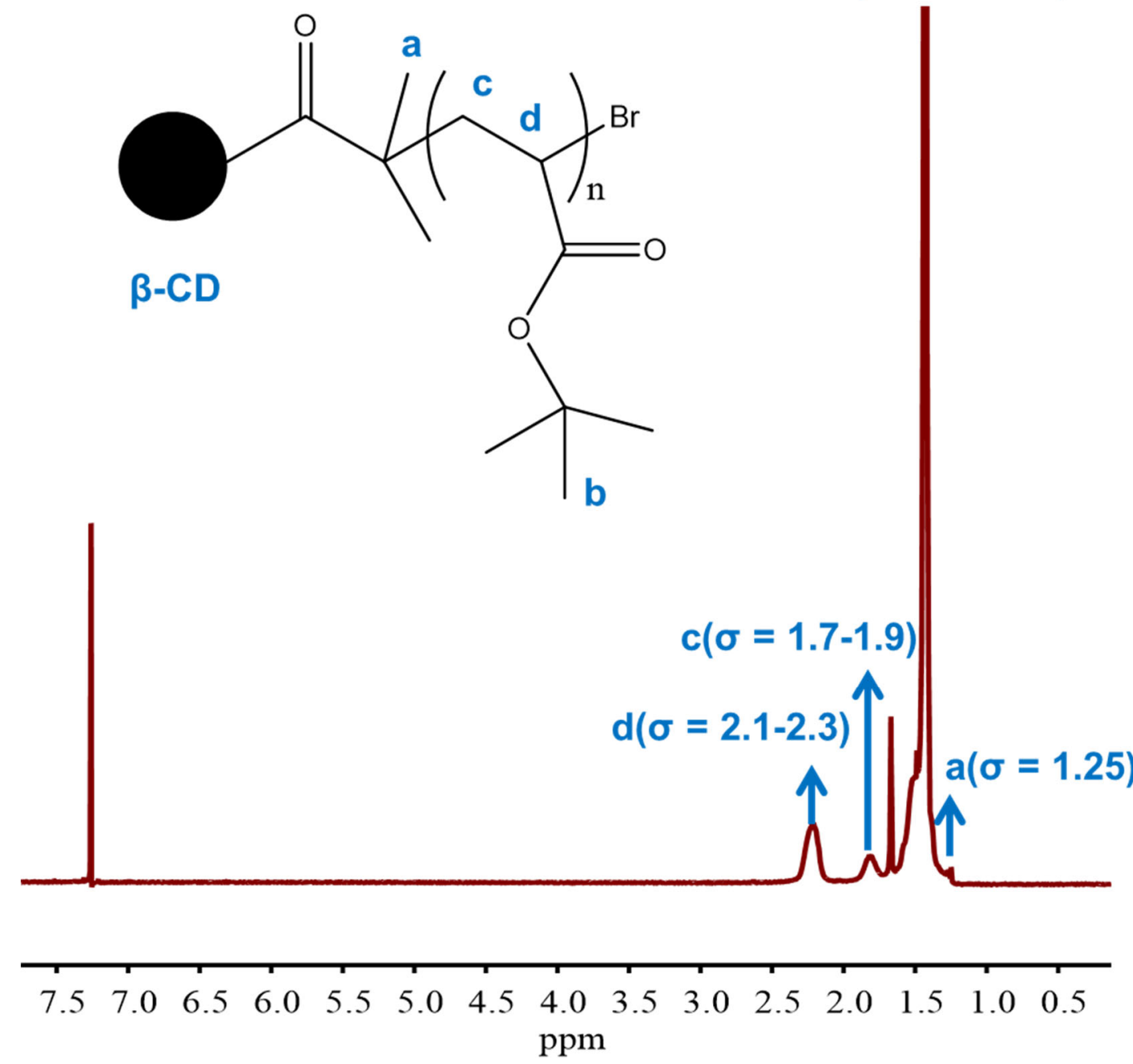

$$
b(\sigma=1.5-1.6)
$$

Figure S2. ${ }^{1} \mathrm{H}$ NMR spectrum of star-like poly(tert-butyl acrylate) ( $\mathrm{P} t \mathrm{BA}$ ) using $\mathrm{CDCl}_{3}$ as solvent. 


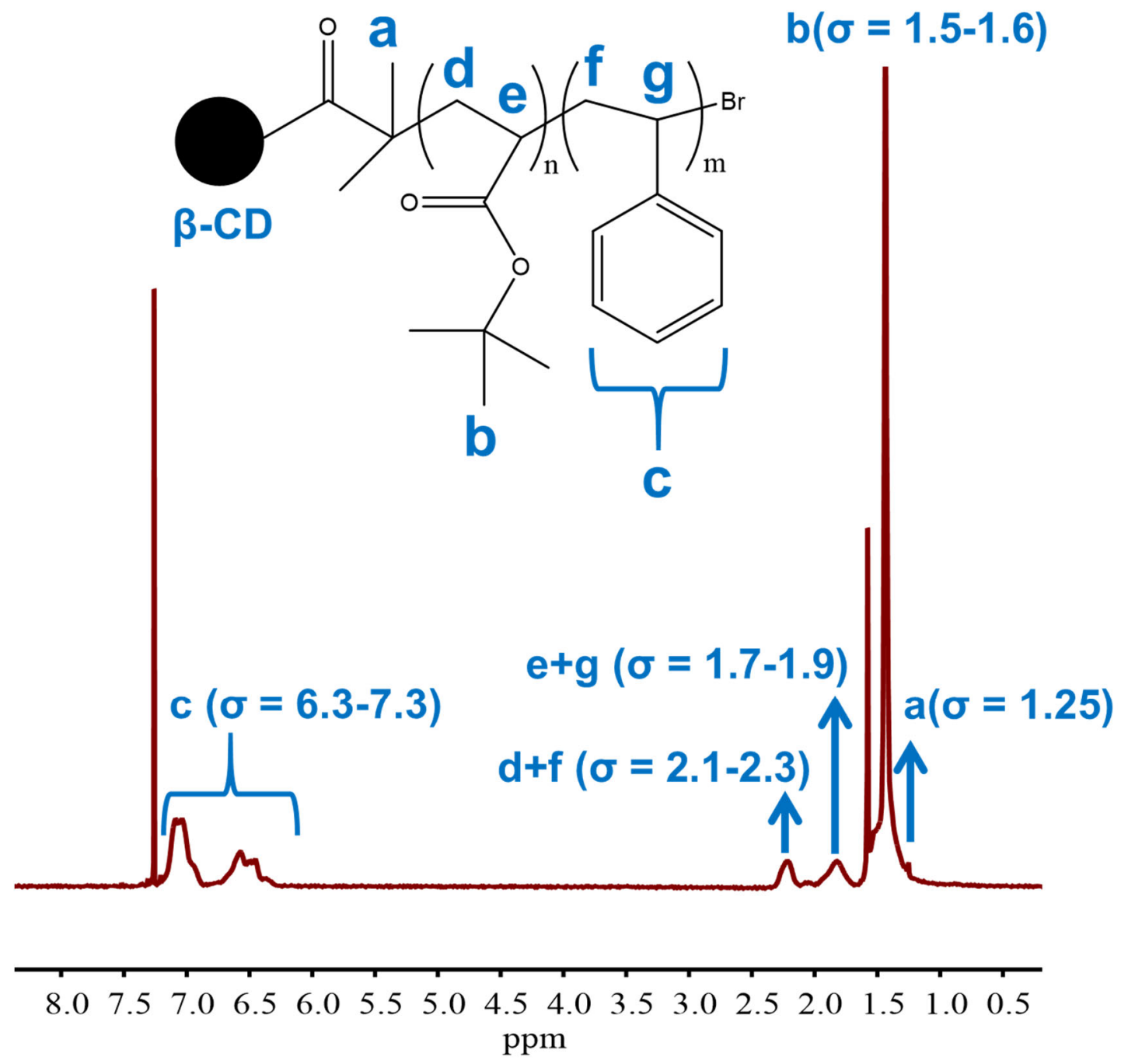

Figure S3. ${ }^{1} \mathrm{H}$ NMR spectrum of star-like poly(tert-butyl acrylate)-block-polystyrene (PtBA- $b$-PS) using $\mathrm{CDCl}_{3}$ as solvent. 


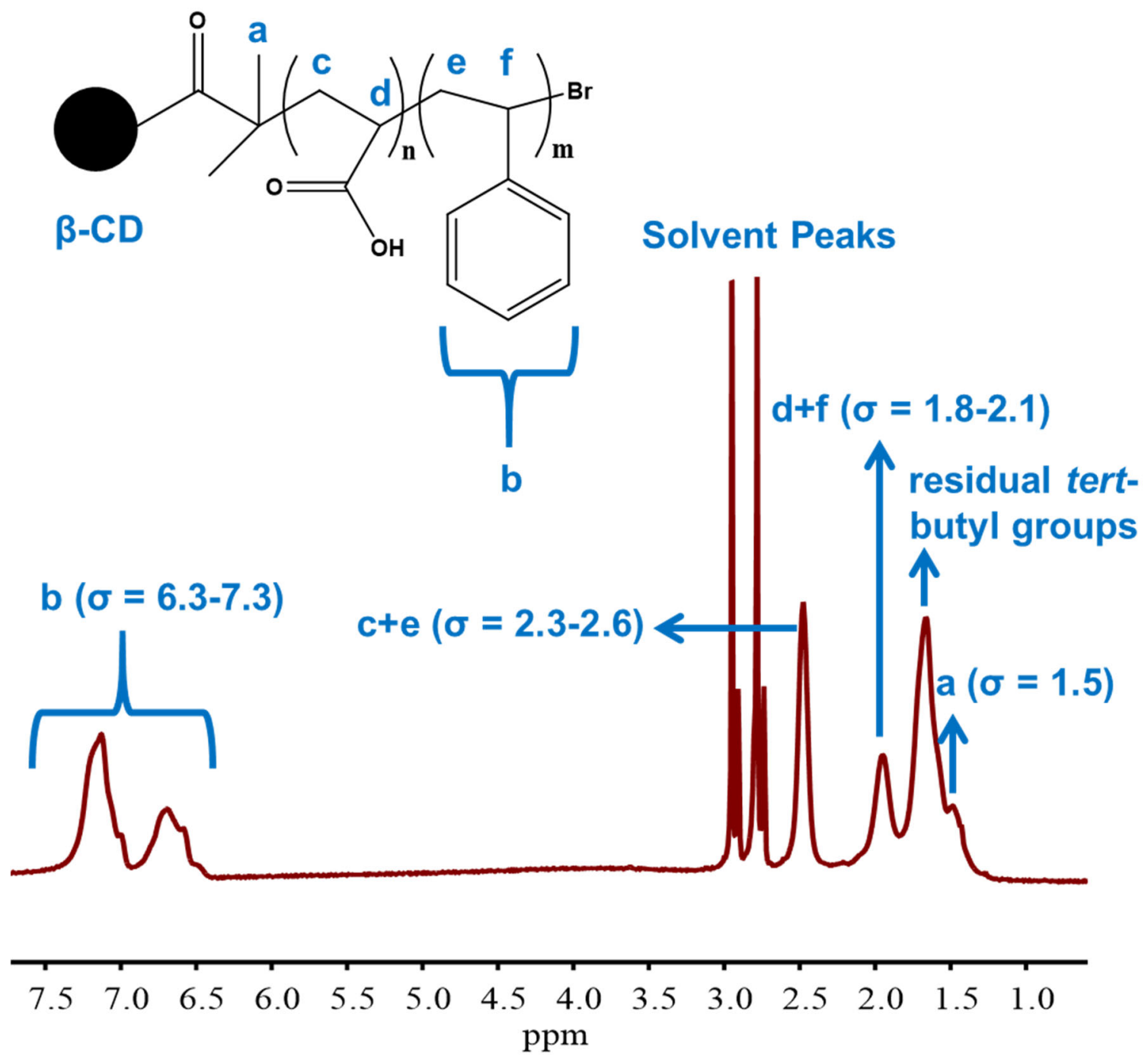

Figure S4. ${ }^{1} \mathrm{H}$ NMR spectra of star-like poly(acrylic acid)-block-polystyrene (PAA- $b$-PS) using $\mathrm{DMF}_{-} \mathrm{d}_{7}$ as solvent. The disappearance of the strong peak around $\sigma=1.5 \mathrm{ppm}$ in Figure S3 indicated the successful hydrolysis and removal of most of the tert-butyl groups, converting P $t \mathrm{BA}$ into PAA in star-like block copolymers. 

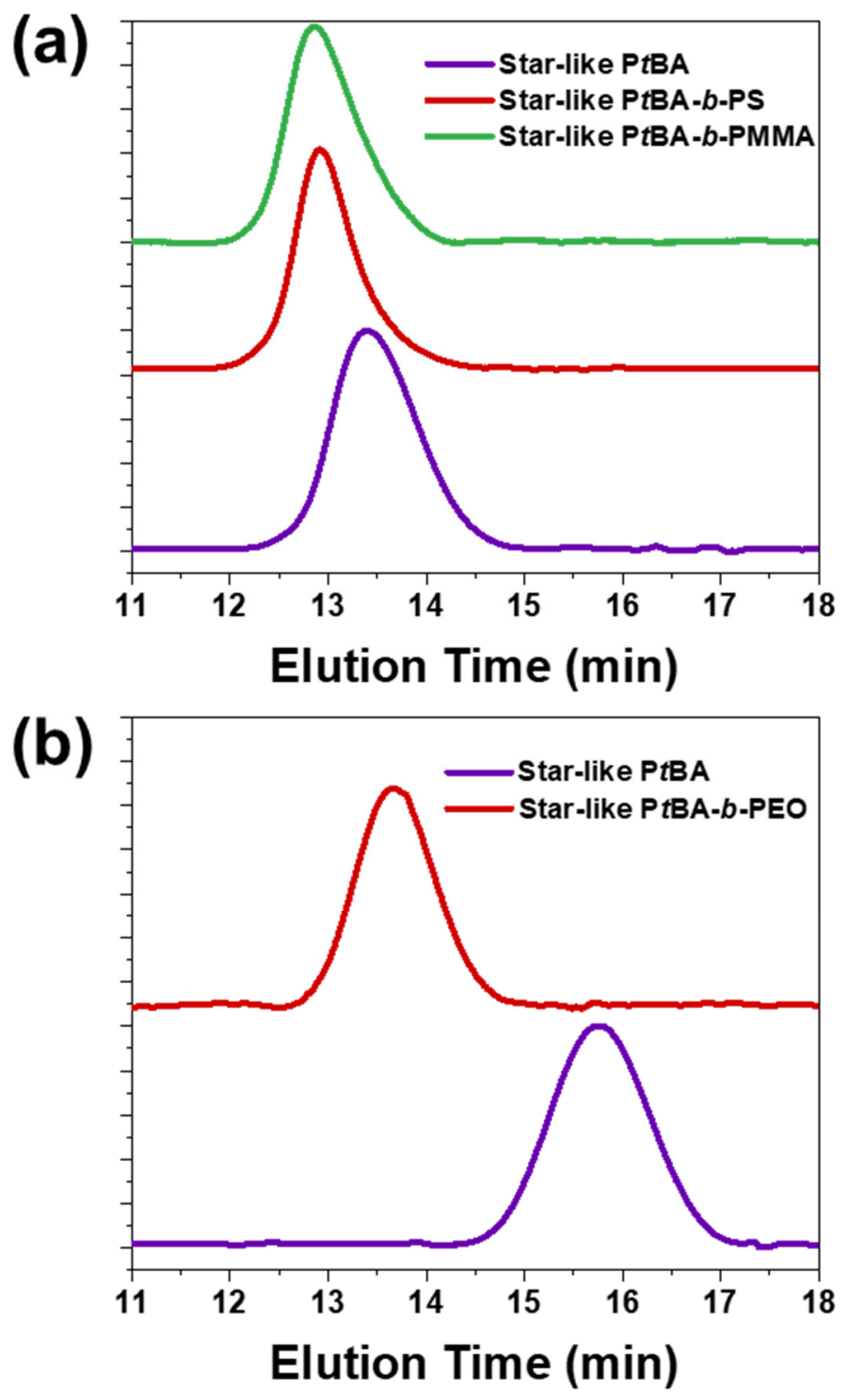

Figure S5. (a) GPC traces of star-like PtBA, PtBA- $b$-PS and PtBA- $b$-PMMA measured by using THF GPC. (b) GPC traces of star-like PtBA, P $t$ BA- $b$-PEO measured by using DMF GPC. 

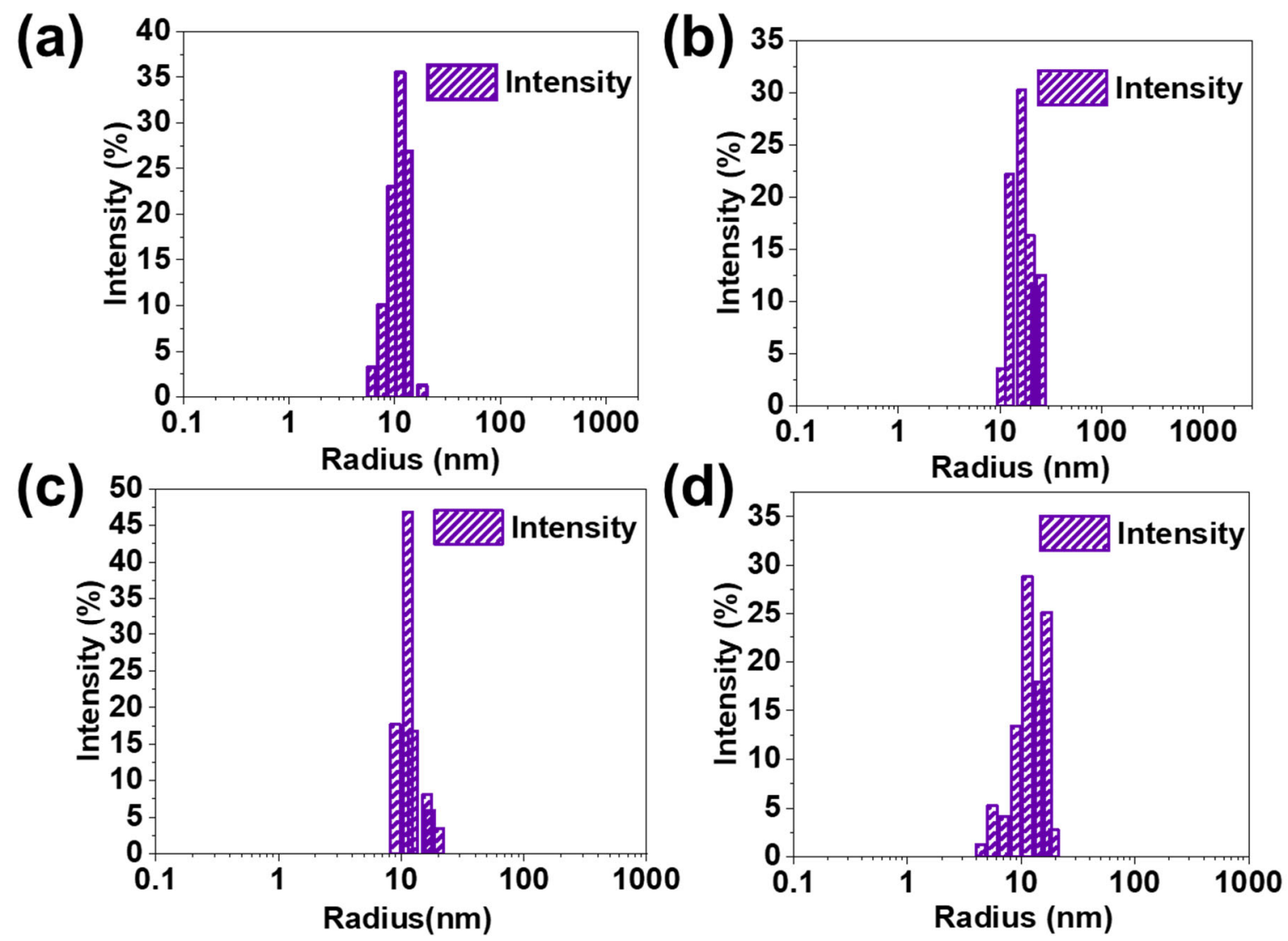

Figure S6. Dynamic light scattering (DLS) characterization using DMF as solvent on (a) star-like PAA- $b$-PS (PAA- $b$-PS-2 in Table 1) with $M_{n, P S}=5,100 \mathrm{~g} / \mathrm{mol}$ of PS per chain; (b) star-like PAA$b$-PS (PAA- $b$-PS-4 in Table 1) with $M_{n, P S}=9,200 \mathrm{~g} / \mathrm{mol}$ of PS per chain; (c) star-like PAA- $b$ PMMA (PAA- $b$-PMMA in Table 1) with $M_{n, P M M A}=5,300 \mathrm{~g} / \mathrm{mol}$ of PMMA per chain; and (d) starlike PAA- $b$-PEO (PAA- $b$-PEO in Table 1) with $M_{n, P E O}=5,000 \mathrm{~g} / \mathrm{mol}$ of PEO per chain. 
Table S1. Summary of the hydrodynamic sizes of star-like block copolymer micelles and the corresponding dimensions of PbSe NPs.

\begin{tabular}{ccc}
\hline Samples & Hydrodynamic Size of micelles ${ }^{\mathrm{a}}(\mathrm{nm})$ & $\begin{array}{c}\text { Diameter of PbSe NPs } \\
(\mathrm{nm})\end{array}$ \\
\hline $\begin{array}{c}\text { PAA- } b \text {-PS-2 } \\
\text { (short PS) }\end{array}$ & 10.76 & $5.2 \pm 0.6$ \\
PAA- $b$-PMMA & 11.0 & $5.1 \pm 0.4$ \\
PAA- $b$-PEO & 11.4 & $4.9 \pm 0.5$ \\
$\begin{array}{c}\text { PAA- } b \text {-PS-4 } \\
\text { (intermediate PS) }\end{array}$ & 16.6 & $5.1 \pm 0.5$
\end{tabular}

a. The hydrodynamic sizes of micelles were measured by dynamic light scattering (DLS) using DMF as solvent at $25^{\circ} \mathrm{C}$;

b. The dimensions of PbSe NPs were determined by performing image analysis on TEM images. 
(a)

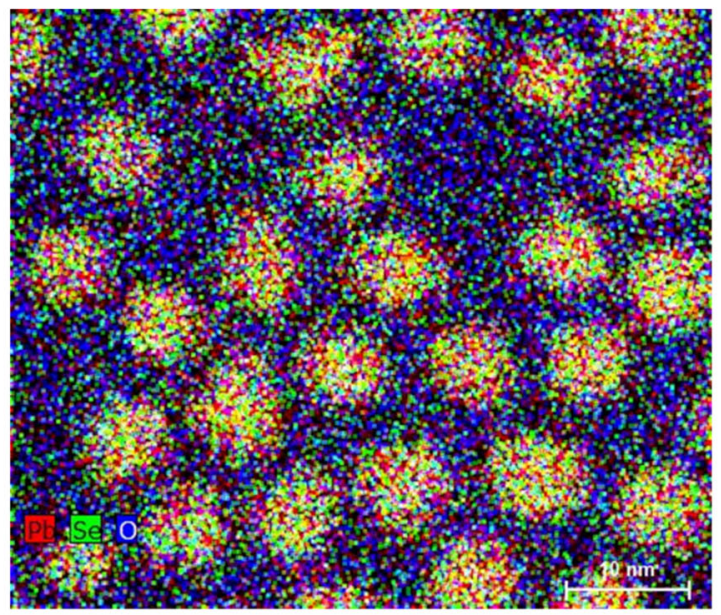

(c)

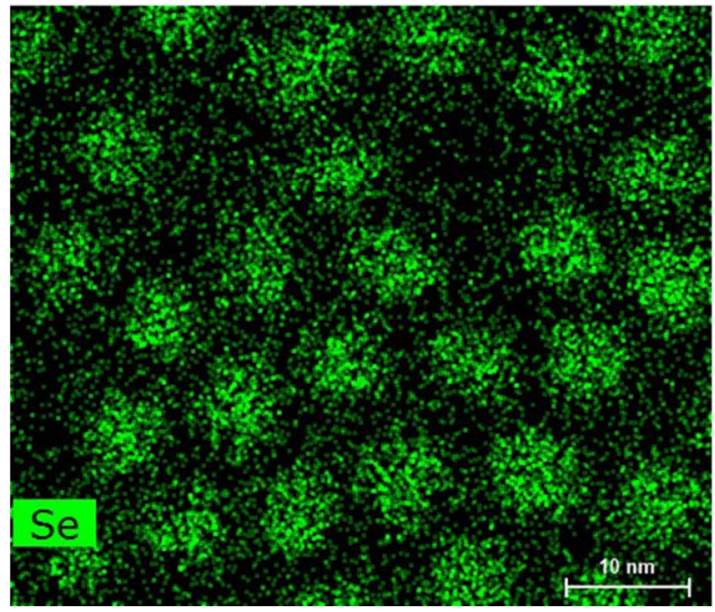

(b)

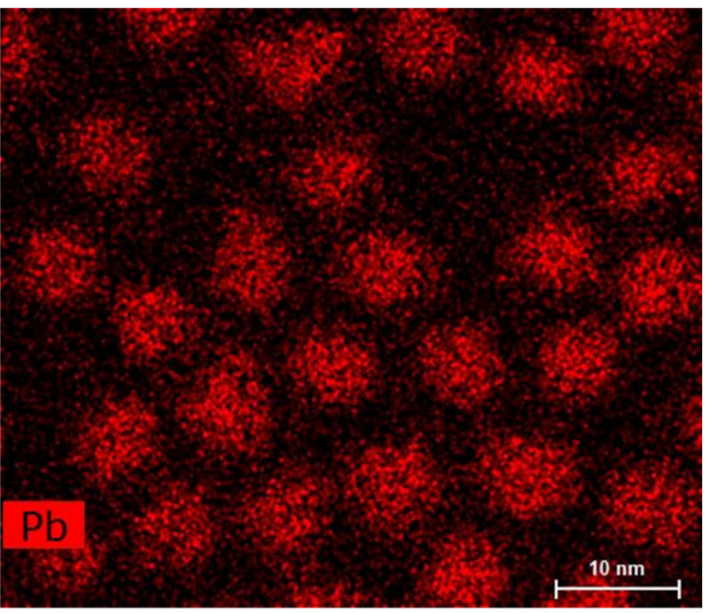

(d)

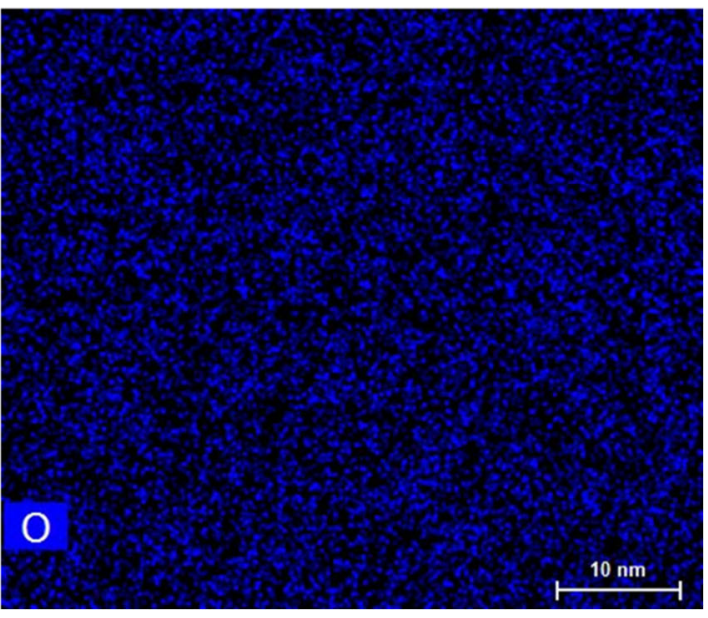

Figure S7. Energy dispersive X-ray (EDX) mapping of PS-ligated PbSe NPs. (a) overall mapping, (b) Lead mapping, (c) Selenium mapping, and (d) Oxygen mapping. Scale bar $=10 \mathrm{~nm}$ in all images. 


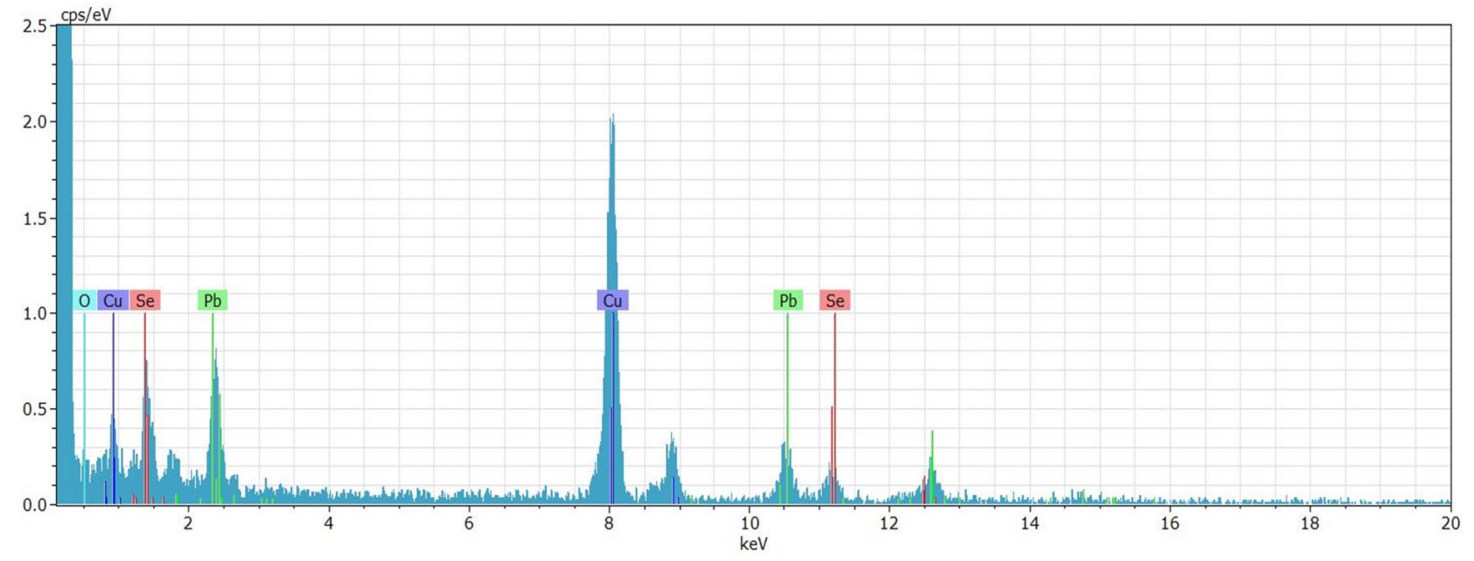

Figure S8. Energy-dispersive X-ray (EDX) spectrum of PS-ligated PbSe NPs. 
Table S2. Energy-dispersive X-ray (EDS) analysis of PS-ligated PbSe NPs.

\begin{tabular}{cccc}
\hline Element & Series & Weight (\%) & Atom (\%) \\
\hline Lead & L-series & 72.16 & 49.69 \\
Selenium & K-series & 27.84 & 50.31
\end{tabular}



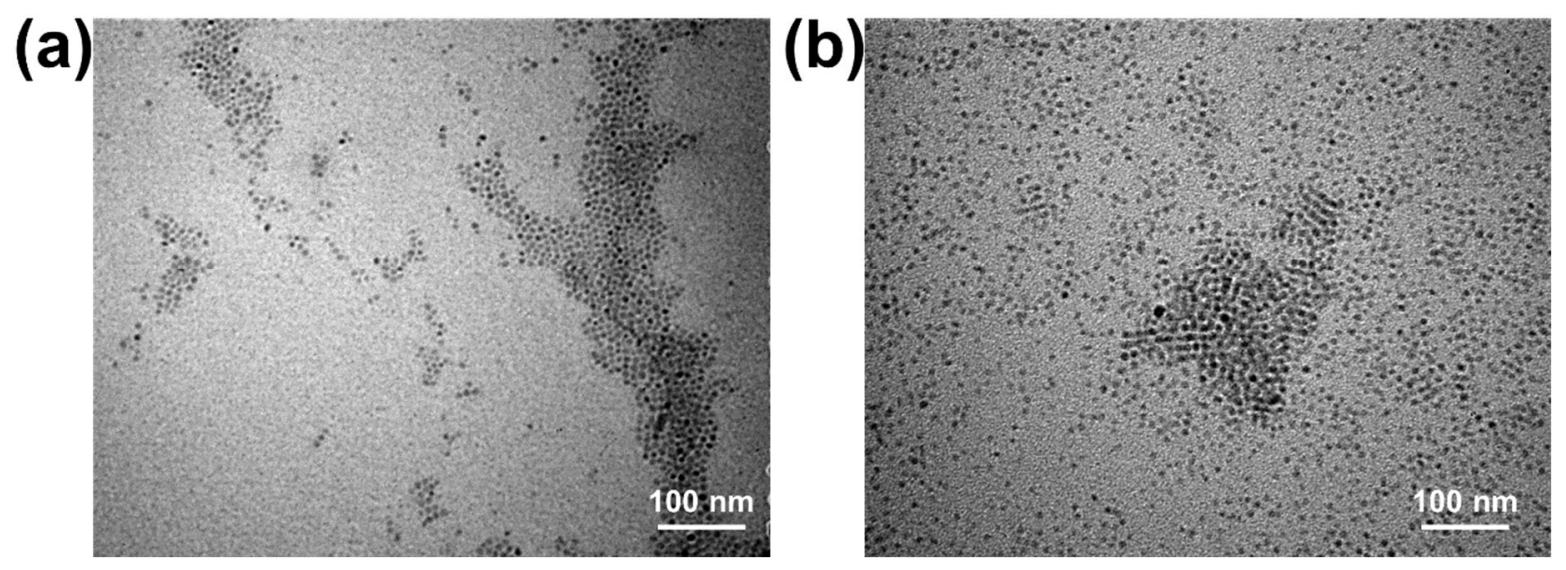

Figure S9. TEM images of PS-ligated (a) CdSe NPs with an average diameter of $8.0 \pm 0.7 \mathrm{~nm}$ and (b) PbTe with an average diameter of $7.9 \pm 1.2 \mathrm{~nm}$ synthesized using star-like PAA- $b$-PS block copolymers as nanoreactors (PAA- $b$-PS-3 in Table 1). 

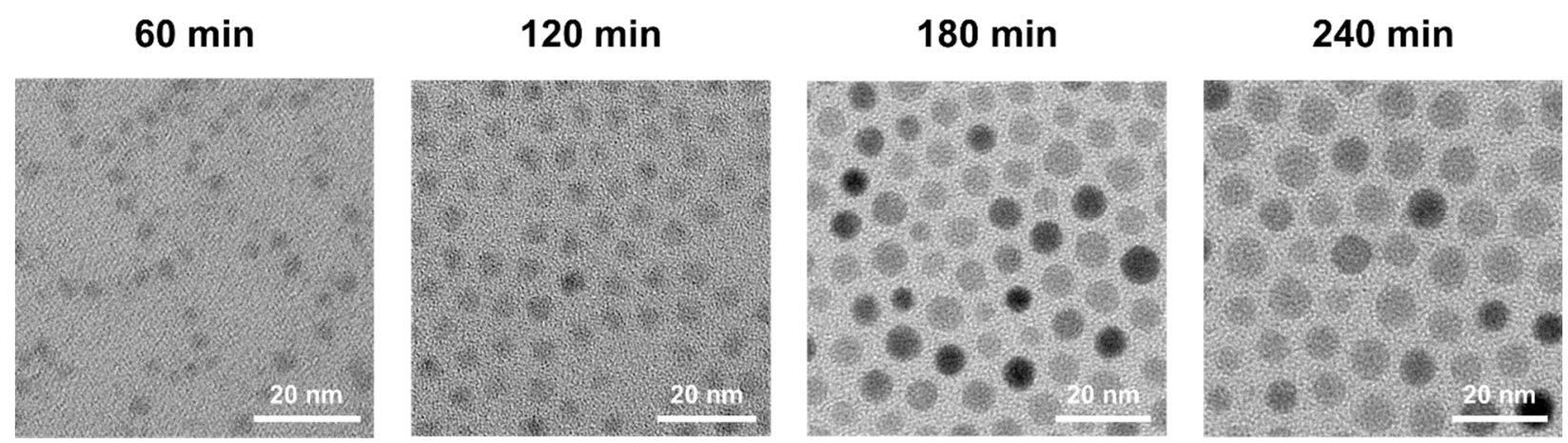

Figure S10. TEM images of PS-ligated PbSe NPs crafted by using PAA-b-PS-3 (Table 1) as nanoreactors as a function of reaction time. 

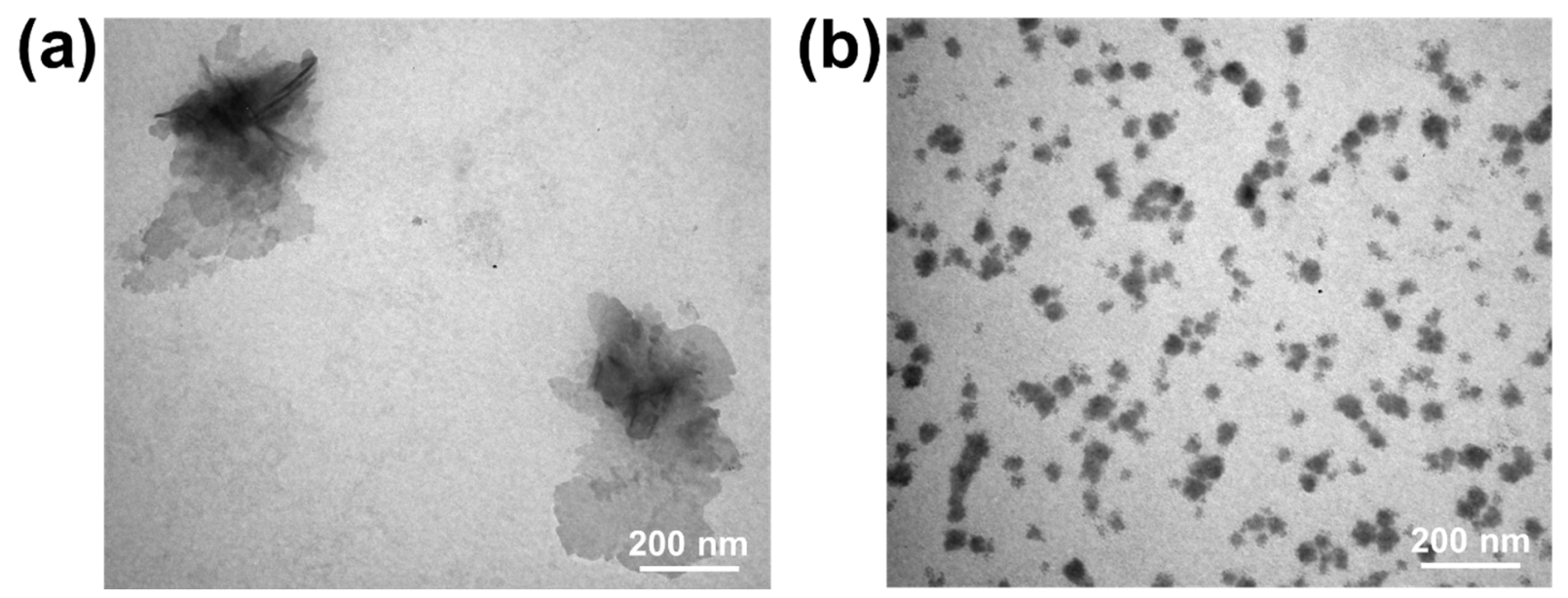

Figure S11. TEM images of PbSe NPs synthesized (a) without star-like block copolymers as nanoreactors and (b) with linear PAA- $b$-PS block copolymers as nanoreactors. 


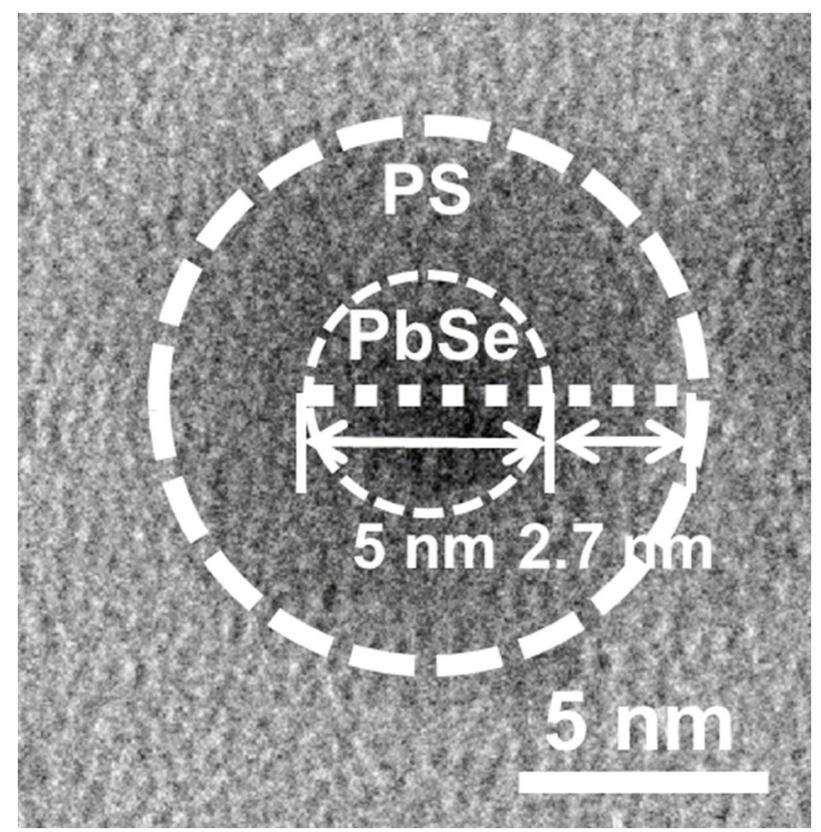

Figure S12. TEM image of PS-ligated PbSe NP after being stained by $\mathrm{RuO}_{4}$ vapor. A layer of PS chains can be seen to intimately cover the surface of the PbSe NP. 

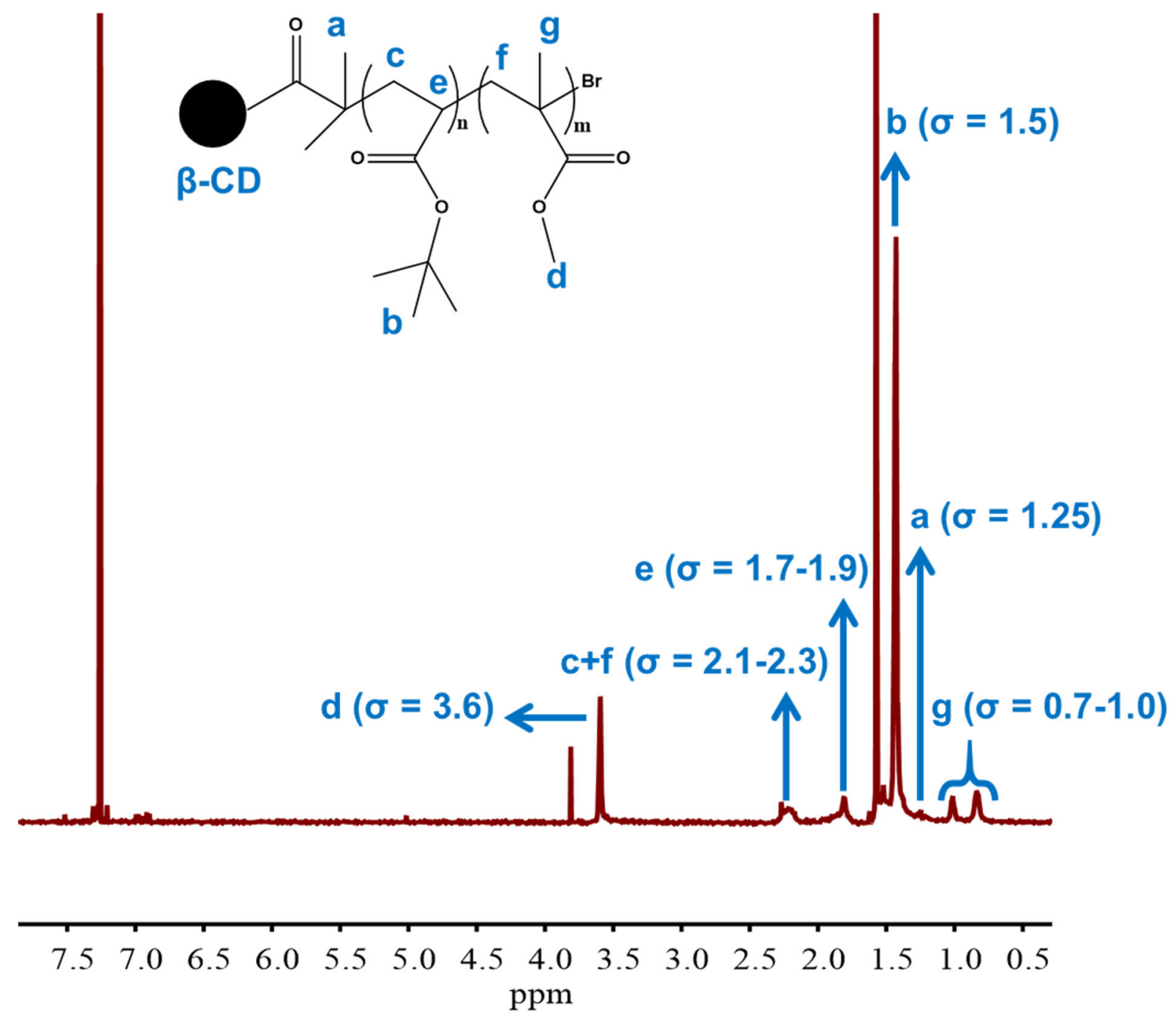

Figure S13. ${ }^{1} \mathrm{H}$ NMR spectrum of star-like poly(tert-butyl acrylate)-block-poly(methyl methacrylate) (PtBA-b-PMMA) using $\mathrm{CDCl}_{3}$ as solvent. 

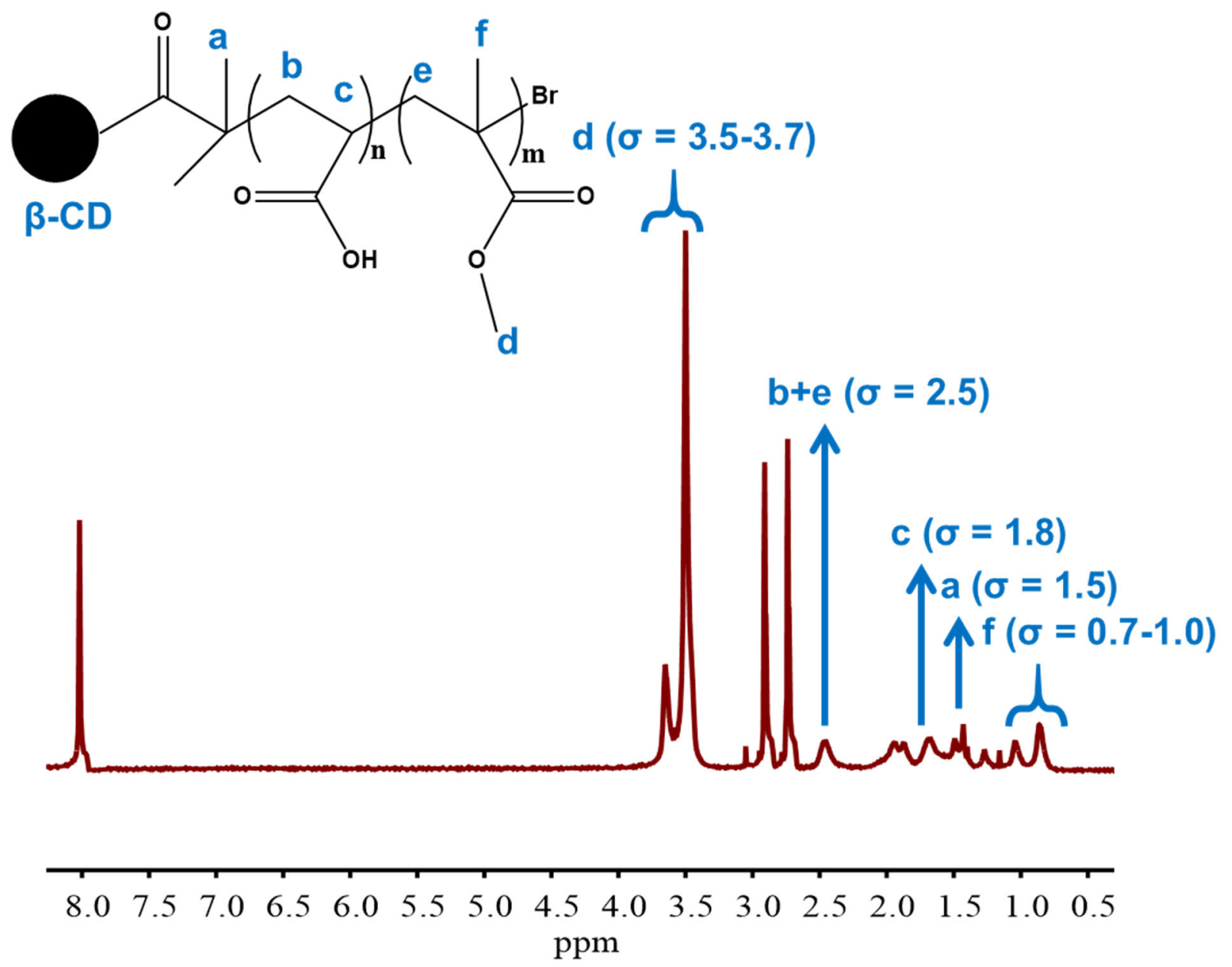

Figure S14. ${ }^{1} \mathrm{H}$ NMR spectrum of star-like poly(acrylic acid)-block-poly(methyl methacrylate) (PAA- $b$-PMMA) using DMF-d 7 as solvent. The disappearance of the strong peak around $\sigma=1.5$ ppm in Figure S11 indicated the successful hydrolysis and removal of the tert-butyl groups, converting P $t$ BA into PAA in the star-like block copolymers. 


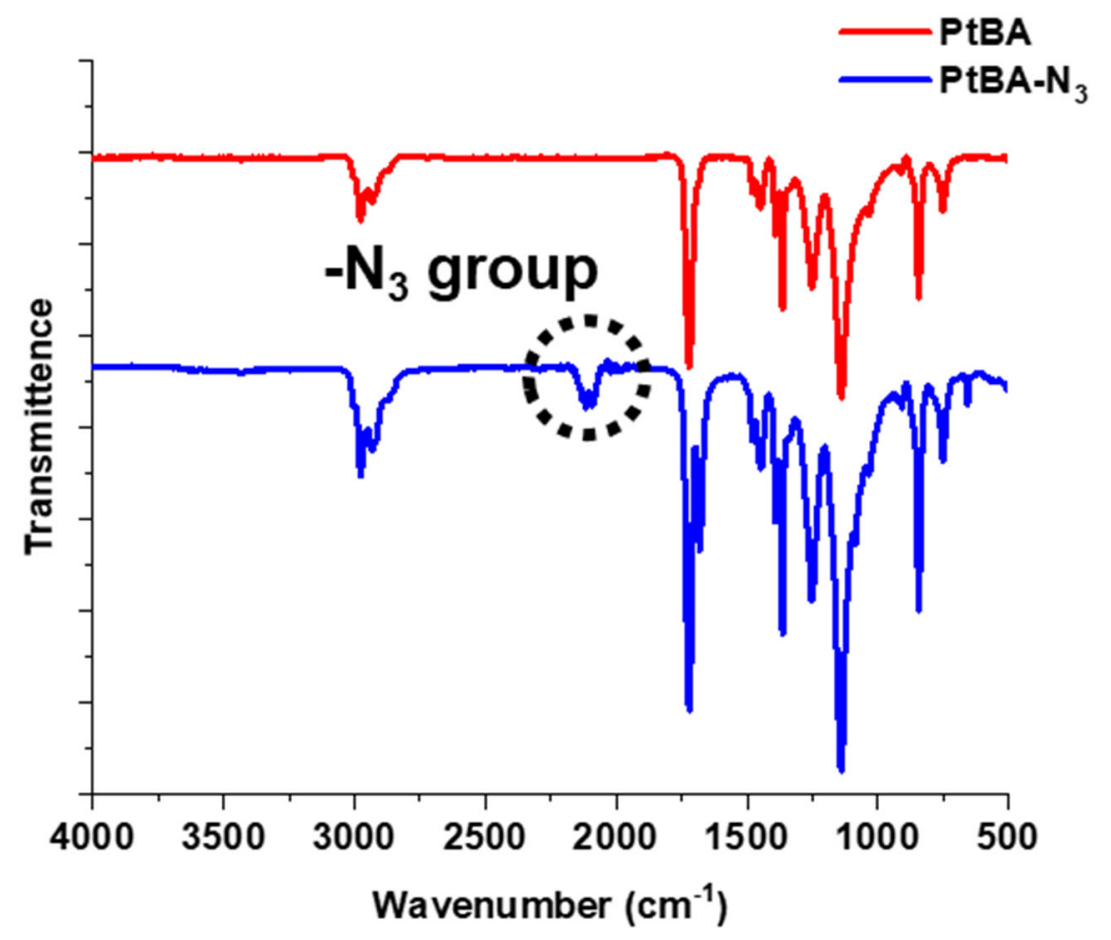

Figure S15. Fourier-transform infrared (FT-IR) spectra of star-like PtBA and $\mathrm{P} t \mathrm{BA}-\mathrm{N}_{3}$. 

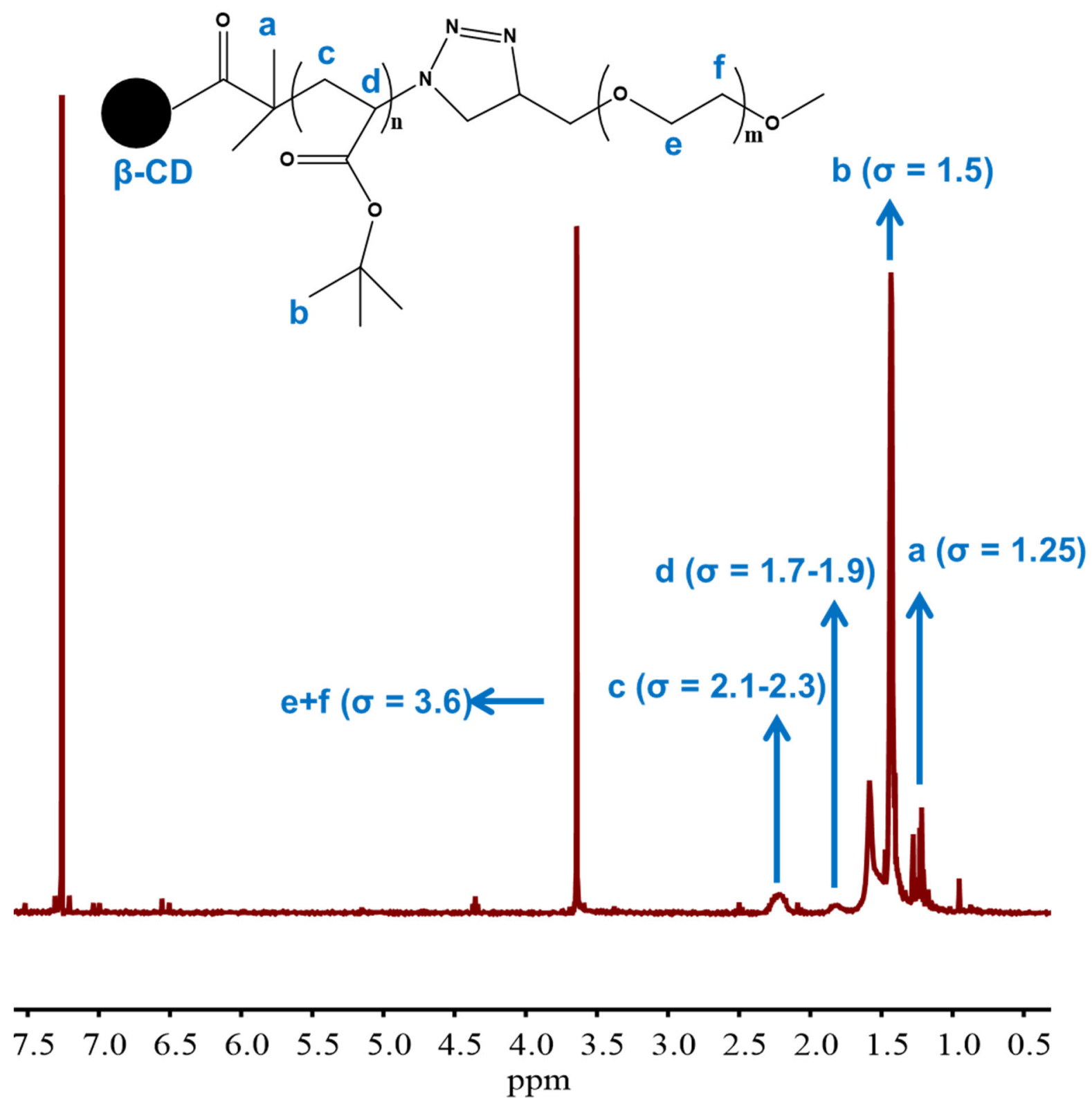

Figure S16. ${ }^{1} \mathrm{H}$ NMR spectrum of star-like poly(tert-butyl acrylate)-block-poly(ethylene oxide) (PtBA- $b-\mathrm{PEO})$ using $\mathrm{CDCl}_{3}$ as solvent. 


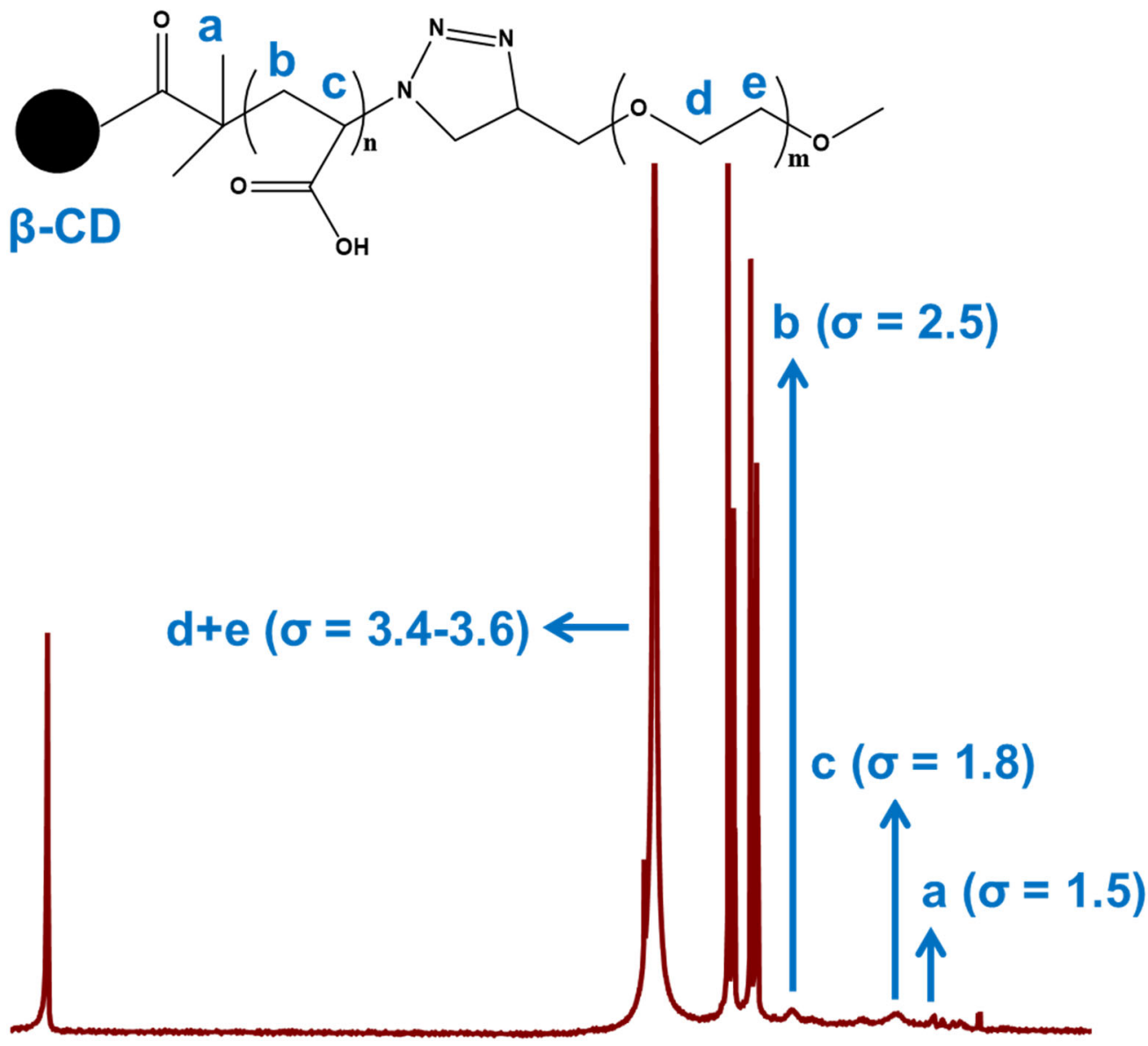

$\begin{array}{lllllllllllllllll}8.0 & 7.5 & 7.0 & 6.5 & 6.0 & 5.5 & 5.0 & 4.5 & 4.0 & 3.5 & 3.0 & 2.5 & 2.0 & 1.5 & 1.0 & 0.5\end{array}$

ppm

Figure S17. ${ }^{1} \mathrm{H}$ NMR spectrum of star-like poly(acrylic acid)-block-poly(ethylene oxide) (PAA$b$-PEO) using DMF- $\mathrm{d}_{7}$ as solvent. The disappearance of the strong peak around $\sigma=1.5 \mathrm{ppm}$ in Figure S14 indicated the successful hydrolysis and removal of the tert-butyl groups, converting P $t$ BA into PAA in the star-like block copolymers. 


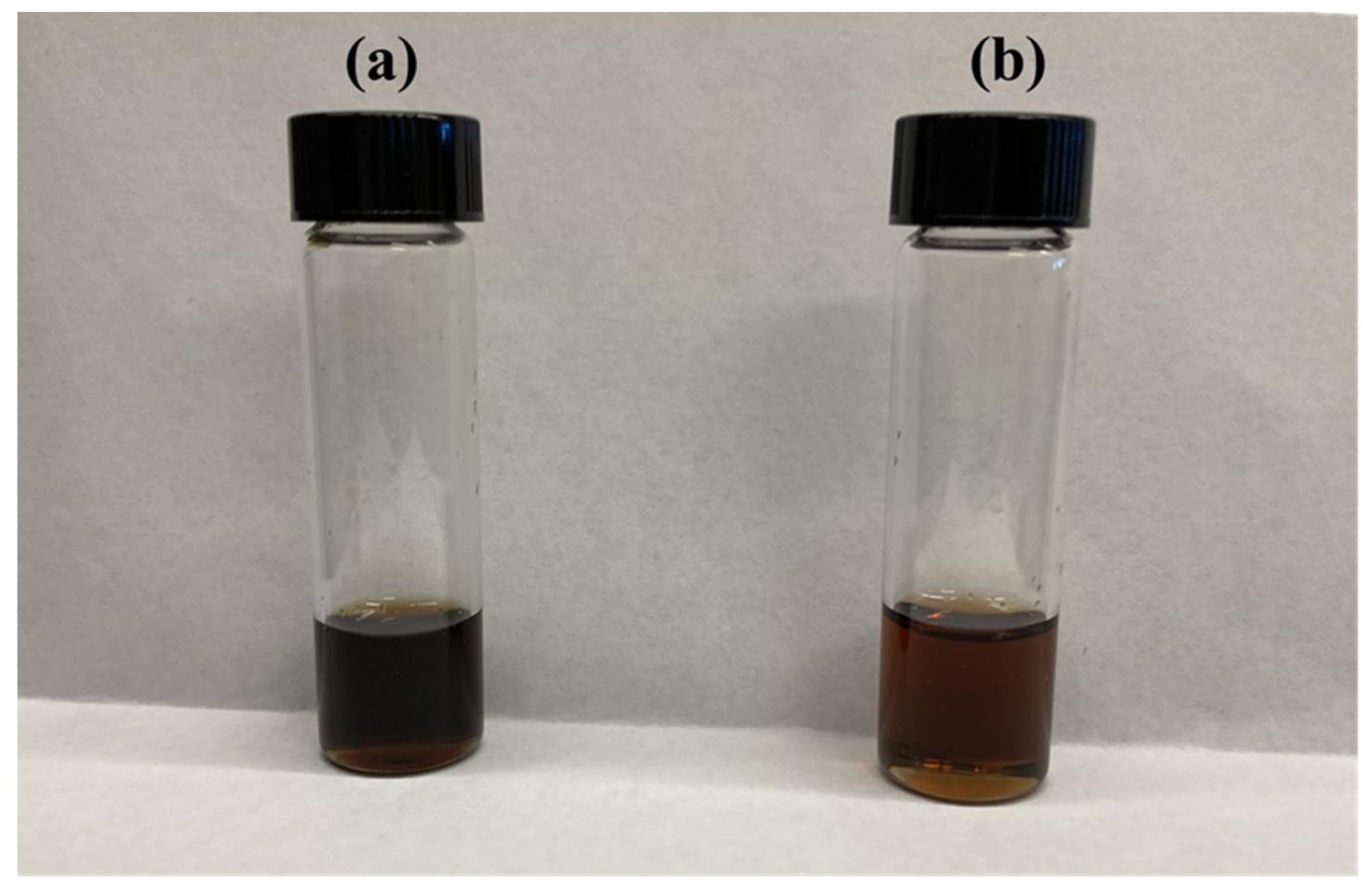

Figure S18. Digital image of PEO-ligated PbSe NPs dispersed in (a) trichloroethylene (TCE) and (b) water. 


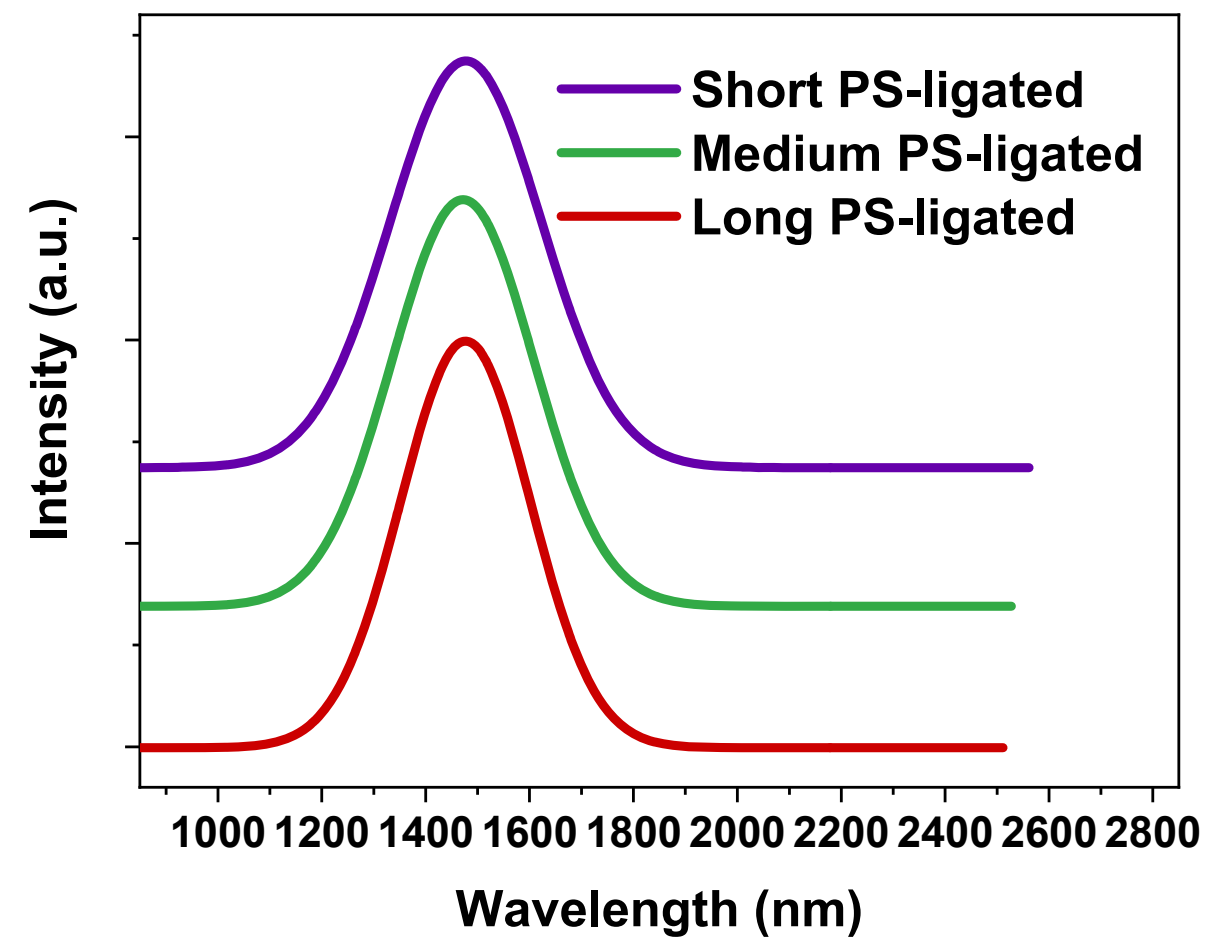

Figure S19. NIR photoluminescence (PL) spectra of $\sim 5-\mathrm{nm}$ PbSe NPs ligated with different length of PS (templated by Sample 2 (short PS chains), Sample 6 (intermediate PS chains), and Sample 7 (long PS chains), respectively; Table S1) 
(a)

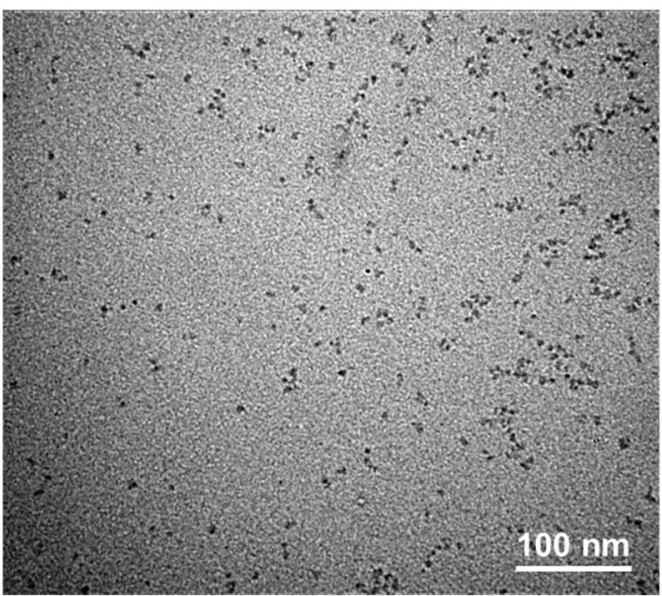

(b)

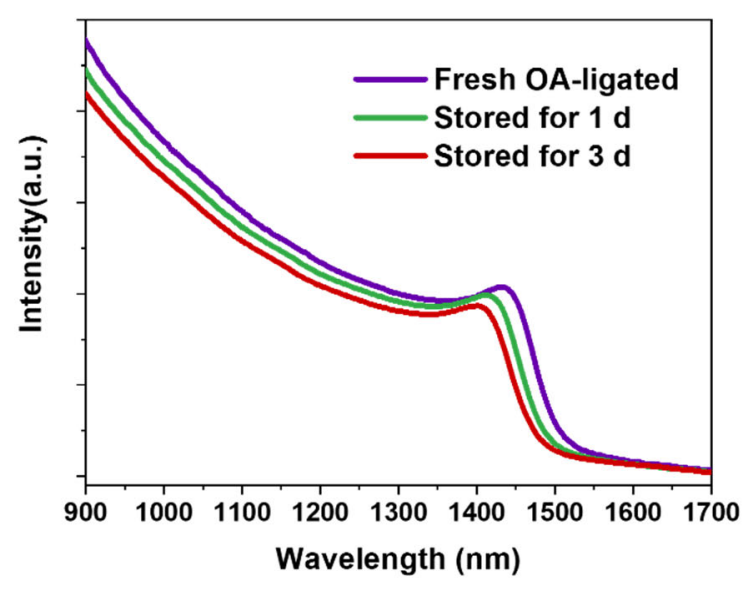

Figure S20. (a) TEM image of conventional oleic acid-ligated (OA-ligated) PbSe NPs with an average diameter of approximately $5 \mathrm{~nm}$. (b) The corresponding UV-Vis-NIR absorption spectra of OA-ligated PbSe NPs as a function of time. 
(a)

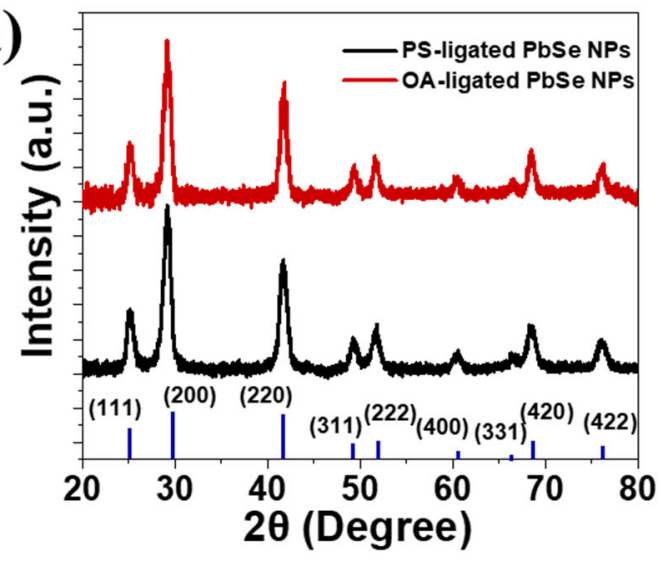

(b)

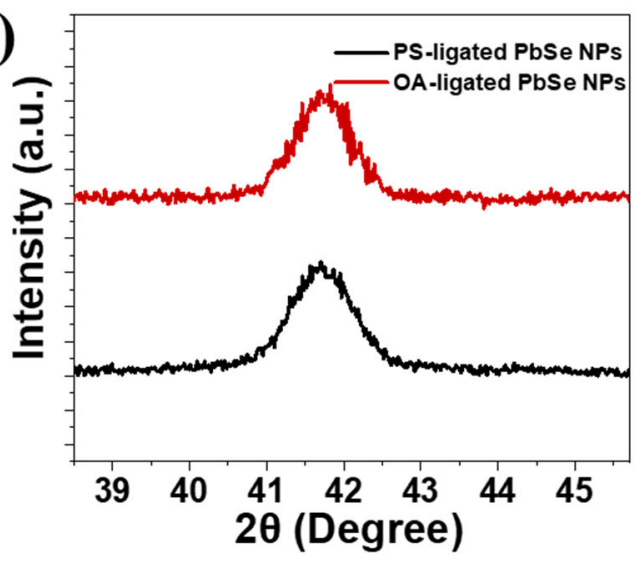

Figure S21. (a) XRD profiles of 5-nm PbSe NPs ligated with PS and OA, respectively. The blue lines represent the standard XRD profile of PbSe (JCPDS \#06-0354). (b) Close-up XRD profiles of 5-nm PbSe NPs ligated with PS and OA, respectively. 


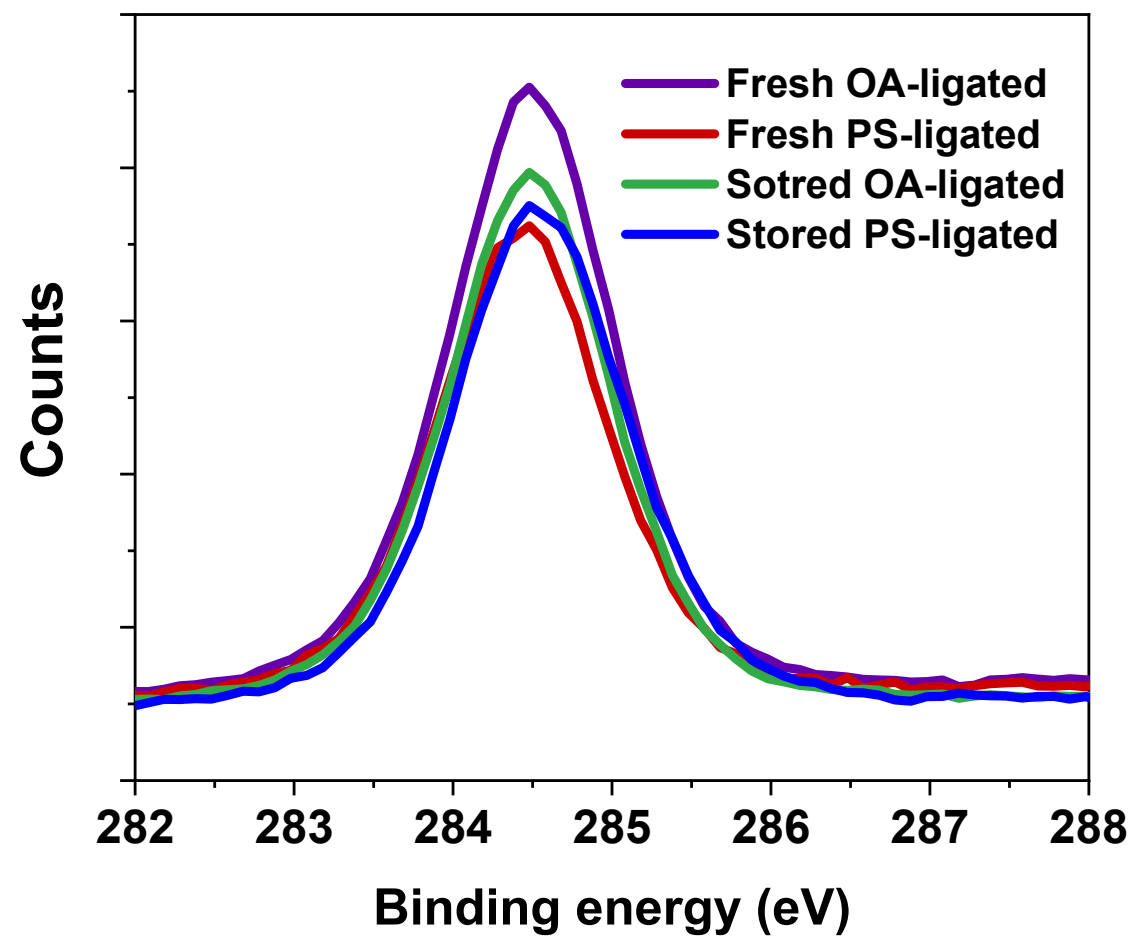

Figure S22. X-ray photoelectron spectroscopy (XPS) profiles of C 1s levels of OA-ligated and PS-ligated PbSe NPs before and after being stored in ambient conditions for 7 days, serving as internal standard for the calibration of the values of binding energy shown in Figure 5. 
Table S3. Hansen solubility parameters of different polymers in trichloroethylene (TCE).

\begin{tabular}{cccccc}
\hline Compound & \multicolumn{4}{c}{ Hansen Solubility Parameters } & Relative \\
\cline { 2 - 5 } & $\begin{array}{c}\text { Dispersion } \\
\left(\mathrm{MPa}^{0.5}\right) \\
\sigma_{d}\end{array}$ & $\begin{array}{c}\text { Polar Interaction } \\
\left(\mathrm{MPa}^{0.5}\right) \\
\sigma_{p}\end{array}$ & $\begin{array}{c}\text { Hydrogen } \\
\text { Bonding } \\
\left(\mathrm{MPa}^{0.5}\right) \\
\sigma_{h}\end{array}$ & $\begin{array}{c}\text { Interaction } \\
\text { Radius } \\
R_{0}\end{array}$ & $\begin{array}{c}\text { Energy } \\
\text { Difference } \\
R_{a} / R_{0}\end{array}$ \\
\hline $\mathrm{TCE}^{\mathrm{a}}$ & 18.0 & 3.1 & 5.3 & - & - \\
$\mathrm{PMMA}^{\mathrm{a}}$ & 16.2 & 6.8 & 5.7 & 9.1 & 0.5690 \\
$\mathrm{PEO}^{\mathrm{b}}$ & 17.3 & 3.0 & 9.4 & 17.1 & 0.2534 \\
$\mathrm{PS}^{\mathrm{a}}$ & 20 & 5.0 & 1.0 & 7.0 & 0.8734
\end{tabular}

a. The values of the Hansen solubility parameters of TCE, PMMA, and PS were retrieved from literature. ${ }^{1}$

b. The values of the Hansen solubility parameters of PEO were also reported in literature. ${ }^{2}$ 


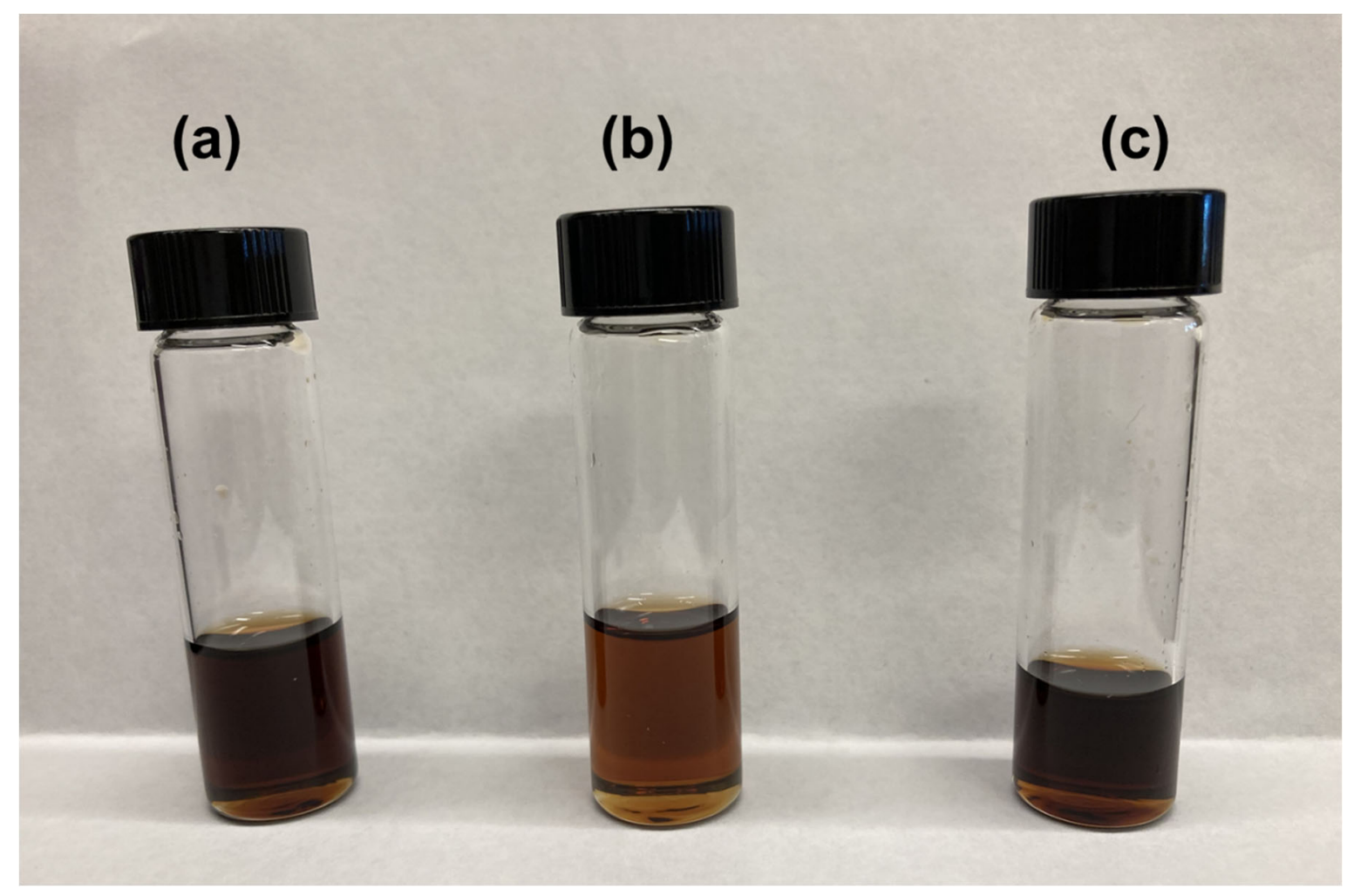

Figure S23. Digital image of (a) PS-ligated, (b) PMMA-ligated, and (c) PEO-ligated PbSe NPs dispersed in trichloroethylene (TCE), demonstrating excellent colloidal stability.

\section{References}

(1) Hansen, C. M., Hansen solubility parameters: a user's handbook. CRC press: 2007.

(2) Jankovic, S.; Tsakiridou, G.; Ditzinger, F.; Koehl, N. J.; Price, D. J.; Ilie, A. R.; Kalantzi, L.; Kimpe, K.; Holm, R.; Nair, A.; Griffin, B.; Christoph, S.; Kuentz, M., Application of the solubility parameter concept to assist with oral delivery of poorly water-soluble drugsa PEARRL review. J. Pharm. Pharmacol. 2019, 71, 441-463. 